\title{
Effects of vegetation restoration on the spatial distribution of soil moisture at the hillslope scale in semi-arid regions
}

\author{
Lei Yang, Liding Chen *, Wei Wei \\ State Key Laboratory of Urban and Regional Ecology, Research Center for Eco-Environmental Sciences, Chinese Academy of Sciences, Beijing 100085, China
}

\section{A R T I C L E I N F O}

\section{Article history:}

Received 27 February 2014

Received in revised form 22 August 2014

Accepted 25 September 2014

Available online 10 October 2014

\section{Keywords:}

Soil moisture

Hillslope

Spatial variation

Vegetation restoration

Semi-arid

\begin{abstract}
A B S T R A C T
Soil moisture is important for plant growth in semi-arid ecosystems. In this study, spatial variations in soil moisture at depths of 0-6 $\mathrm{m}$ on seven hillslopes of China's Loess Plateau planted with korshinsk peashrub were analyzed based on soil moisture observations. The objective of this study was to compare the spatial patterns in soil moisture in shallow and deep soil layers at the hillslope scale under the influence of large-scale vegetation restoration. The results showed that: (1) the topographic wetness index was positively correlated with soil moisture near the surface $(0-1 \mathrm{~m})$, but negatively correlated with soil moisture at depths below $2 \mathrm{~m}$; and (2) the negative relationship was found between biomass and soil moisture content in deep layers. Soil moisture in shallow layers was more likely to be affected by topographic factors. However, comparisons of soil moisture at different slope positions indicated that the effect of topographic factors on the variability of deep soil moisture was altered, mainly because plants with different biomasses may differ in their consumption of soil water and thus cause greater spatial variations in deep soil moisture. The introduced vegetation may alter the spatial pattern of deep soil moisture influenced by topographic factors at the hillslope scale, and the biomass may have a determining role in the spatial variation of deep-layer soil moisture content.
\end{abstract}

(c) 2014 Elsevier B.V. All rights reserved.

\section{Introduction}

Soil moisture is important for plant growth and plays a critical role in many surface processes in terrestrial ecosystems (Legates et al., 2011; Porporato et al., 2002). Characterizing soil moisture variations across a range of spatial and temporal scales is important for both theoretical and practical applications (Ivanov et al., 2010). Soil moisture distributions have important implications for runoff (Price, 2011), agriculture (Hebrard et al., 2006) and vegetation restoration (Engelbrecht et al., 2007). Understanding the spatial variability of soil moisture and its influencing factors will provide a basis for optimizing the spatial allocation of vegetation restoration efforts. Soil moisture and its spatial variation are closely related to vegetation (Ferreira et al., 2007; Vivoni et al., 2008). This is particularly true for ecosystems in arid and semi-arid environments (Sanchez-Mejia et al., 2014). The interaction between soil moisture and vegetation is likely to become a critical issue of great interest to researchers in hydrology, ecology, and geography.

There is growing agreement in the scientific literatures that many factors can affect spatial variation in soil moisture. In addition to vegetation attributes, topographic factors, soil depth and soil properties all play key roles (Gómez-Plaza et al., 2000; Qiu et al., 2001). Specifically, small-scale topographic variability results in significant local redistribution of precipitation and surface runoff (Crave and Gascuel-Odoux,

\footnotetext{
* Corresponding author. Tel.: +8610 62943840; fax: +861062849014.

E-mail address: liding@rcees.ac.cn (L. Chen).
}

1997). This redistribution inevitably affects the spatial variation in soil moisture (Legates et al., 2011; Meerveld and McDonnell, 2006). For example, the topographic wetness index (TWI), which is based on topographic factors (upslope contributing areas and slope gradient), can represent soil moisture conditions under the influence of topographic factors well (Ali et al., 2010; Cantón et al., 2004; Western et al., 2004). However, soil moisture at different depths may have a different response to influencing factors in afforested land (Venkatesh et al., 2011).

The Loess Plateau of China is covered by loess soil nearly $100 \mathrm{~m}$ thick with a loose soil structure (Chen et al., 2007). Very little of the groundwater in this region can be used by plants due to the depth of the water table (Chen et al., 2008a). In this region, introduced vegetation has become the main vegetation type due to the large-scale implementation of "Grain to Green Program" initiated by the central government in 1999 (Chen et al., 2010). However, unlike native plants, introduced vegetation usually has a higher water demand and annual rainfall levels cannot supply sufficient water for growth (Chen et al., 2008a; Wang et al., 2010). Introduced plants in this region are thus forced to develop deep and robust root systems to utilize soil moisture in deep soil layers (Chen et al., 2008a; Yang et al., 2012a). The limited water stored below the surface layers has become a particularly important component of ecosystems in this region. Evaluation of the influence of vegetation restoration on local deep soil moisture in this area is thus urgently needed.

Several recent studies have been conducted on deep soil moisture depletion (Wang et al., 2010; Yang et al., 2012a) and regional water yield reduction (Sun et al., 2006) influenced by large-scale vegetation 
restoration in the Loess Plateau. However, these studies paid limited attention to the question of how spatial variations in deep soil moisture are influenced by vegetation restoration. Topography is a particularly important determinant of soil moisture patterns in this region (Qiu et al., 2001; Zhu and Shao, 2008). Because soil properties are homogeneous in small loess watersheds (Jin et al., 2011), the topography becomes more important in the control of soil moisture dynamics and redistribution (Qiu et al., 2001). Specifically, because deep soil moisture is an important stable water source for introduced vegetation, understanding the spatial variation in deep soil moisture is fundamental for the possible optimization of vegetation restoration.

As discussed above, soil moisture is significantly influenced by vegetation and topography in such regions. Identifying the interactions between soil moisture and vegetation/topography thus improves understanding of the mechanisms that organize vegetation structure in human-influenced ecosystems. However, the main factors affecting spatial variations in deep soil moisture under the influence of vegetation restoration still requires urgent elucidation. Due to the current observational limitations in the subsurface, most empirical studies can only focus on spatial variations in shallow surface water (Ivanov et al., 2010). The hillslope is a basic component of the landscape and is of primary importance in understanding the physical mechanisms that underline the heterogeneity of states and fluxes in simple-geometry topographic units (Ivanov et al., 2010).

This study was designed to compare the soil moisture in shallow and deep soil layers on seven separate hillslopes planted with a typical introduced vegetation, korshinsk peashrub (Caragana korshinskii Kom.), to support more effective restoration policies in arid and semi-arid areas. Therefore, the objectives of this study were (1) to analyze the spatial patterns of soil moisture in different soil layers on hillslopes, (2) to investigate the correlations between spatial patterns of soil moisture and vegetation/topographic features, and (3) to elucidate the main factors affecting spatial distributions in deep soil moisture at the hillslope scale.

\section{Materials and methods}

\subsection{Study area}

The study area is located in Longtan watershed $\left(35^{\circ} 43^{\prime}-35^{\circ} 46^{\prime} \mathrm{N}\right.$, $104^{\circ} 27^{\prime}-104^{\circ} 31^{\prime} \mathrm{E}$ ) in Gansu Province, and covers an area of $16.1 \mathrm{~km}^{2}$. The altitude ranges from $1840 \mathrm{~m}$ to $2260 \mathrm{~m}$ and the landscape is highly fragmented. The study area is a typical hilly semi-arid loess region, with a mean annual temperature of approximately $6.8^{\circ} \mathrm{C}$ and a mean annual precipitation of approximately $386 \mathrm{~mm}$. Most of the rainfall occurs in the form of thunderstorms from July to September. The potential annual evaporation (pan evaporation) is about $1649 \mathrm{~mm}$. The annual averages were derived from meteorological data provided by a meteorological station $0.6 \mathrm{~km}$ from the watershed and represent 45 -year averages (1961-2006). Based on 2008-2012 data from five spatially distributed automatically recording rain gauges, the rainfall pattern has a uniform spatial distribution in the watershed. Loess soil with low fertility is the main soil type in this area; such soils are vulnerable to erosion. Typically they have a loose structure, a high silt content (ca. 81\%), a soil moisture field capacity of $0.180-0.240 \mathrm{~g} / \mathrm{g}$, a saturated moisture content about $0.470 \mathrm{~g} / \mathrm{g}$, and contain little organic matter (ca. 0.2-2.9\%). Soil thickness in the study area varies from $40 \mathrm{~m}$ to $60 \mathrm{~m}$. The predominant vegetation types are introduced vegetation (such as korshinsk peashrub, alfalfa, Chinese red pine, and others), rain-fed crops, and sparse native grass. Water shortage is the major constraint to plant growth in this area, as is typical in semi-arid climatic zones.

\subsection{Observation and analysis}

\subsubsection{Experimental site designs}

Seven hillslopes (East-1, East-2, South-1, South-2, South-3, South-4, and North-1; Fig. 1a) in the study area were selected for investigation of soil moisture variability in different slope positions. All hillslopes were covered with korshinsk peashrub from top to bottom. Korshinsk peashrub is widely planted in the Loess Plateau to reduce soil erosion (Cheng et al., 2009). This plant has a strong taproot (Fig. 1c) and develops fine root systems, and can thus consume soil water stored at depths of more than $10 \mathrm{~m}$ (Chen et al., 2010; Cheng et al., 2005). The korshinsk peashrubs in the study area were planted in 1984 at similar planting densities over different sites for the purposes of decreasing soil erosion and ecological restoration. On each hillslope, five separate experimental sites were located on the upper (position 1), uppermiddle (position 2), middle (position 3), middle-bottom (position 4) and bottom positions (position 5) on each hillslope (Fig. 1a, b). These five sites (from position 1 to position 5 ) were located along the direction of flow from upslope contributing areas. The distance between each experimental site on each hillslope was 30-70 m with the sites having similar slope aspects and slope gradients. The topographic wetness index (TWI) of each site was calculated in ArcGIS® 10.2 using a DEM (Digital Elevation Model) with a resolution of $10 \mathrm{~m}$. Refer to Western et al. (1999) for more information about TWI. The experimental sites selected in this study were near to each other and affected by a unique spatially distributed precipitation.

\subsubsection{Data collection}

The soil moisture content (SMC) at depths of 0-6 m was observed at each experimental site in late August 2012. The SMC was measured 2 weeks after a rainfall of $22 \mathrm{~mm}$, and all field work was completed in 8 days. Soil samples in $20 \mathrm{~cm}$ increments were taken using a drill and stored in sealed aluminum cases to prevent potential water loss prior to laboratory measurement. Measurement of SMC (units: $g / g$ ) for all soil samples was carried out using the gravimetric approach which involves oven-drying for $24 \mathrm{~h}$ at $105{ }^{\circ} \mathrm{C}$. At each slope location (upper, upper-middle, middle, middle-bottom, and bottom), three sampling points were randomly chosen for triplicate samples to obtain the average SMC at each experimental site. Thirty soil samples were collected from each sampling point. The depth-averaged SMC of each experimental site was calculated using Eq. (1):

$S M C_{j}=\frac{1}{i} \sum_{i=1}^{i} S M C_{i}$

where $i$ is the number of measurement layers at site $j$ and $S M C_{i}$ is the mean SMC in layer $i$ calculated from the three sampling points. At depths of $0-1 \mathrm{~m}$ and $1-2 \mathrm{~m}$ there were five measurement layers, and at depths of 2-4 $\mathrm{m}$ and 4-6 $\mathrm{m}$ there were 10 . For the remainder of this paper, SMC0-1 represents the SMC at a depth of 0-1 m, SMC1-2 at 1-2 m, SMC2-4 at 2-4 m, and SMC4-6 at 4-6 m.

Long-term soil moisture observations were also carried out during 2009-2012 on hillslope East-2 (including experimental sites East21, East23, and East25), hillslope South-2 (including experimental sites South21, South23, and South25), and hillslope North-1 (including experimental sites North12, North13, and North14). During 2009-2012, soil moisture measurements in the growing season (from May to October) were made biweekly (beginning and middle of each month) for the $0-2 \mathrm{~m}$ profile in $20 \mathrm{~cm}$ increments. The SMC data were also obtained using the gravimetric approach. Temporally averaged SMC data calculated from long-term soil moisture observations were used to help identify soil moisture spatial variability related to slope position.

The latitude, longitude, and elevation were determined for each experimental site using a Garmin GPS60. Slope gradients and the slope aspect of each site were determined using a compass during field investigations. Slope gradient was recorded in degrees. Slope aspect (clockwise from north), which is a circular variable, was transformed into cos (aspect). Investigation of the structure of the vegetation was conducted at each slope location. The stand density (plants/ha), canopy density (the percentage of the area covered by shrub canopy), shrub height $(\mathrm{m})$, canopy length (measured along the direction of flow), and 
(a)

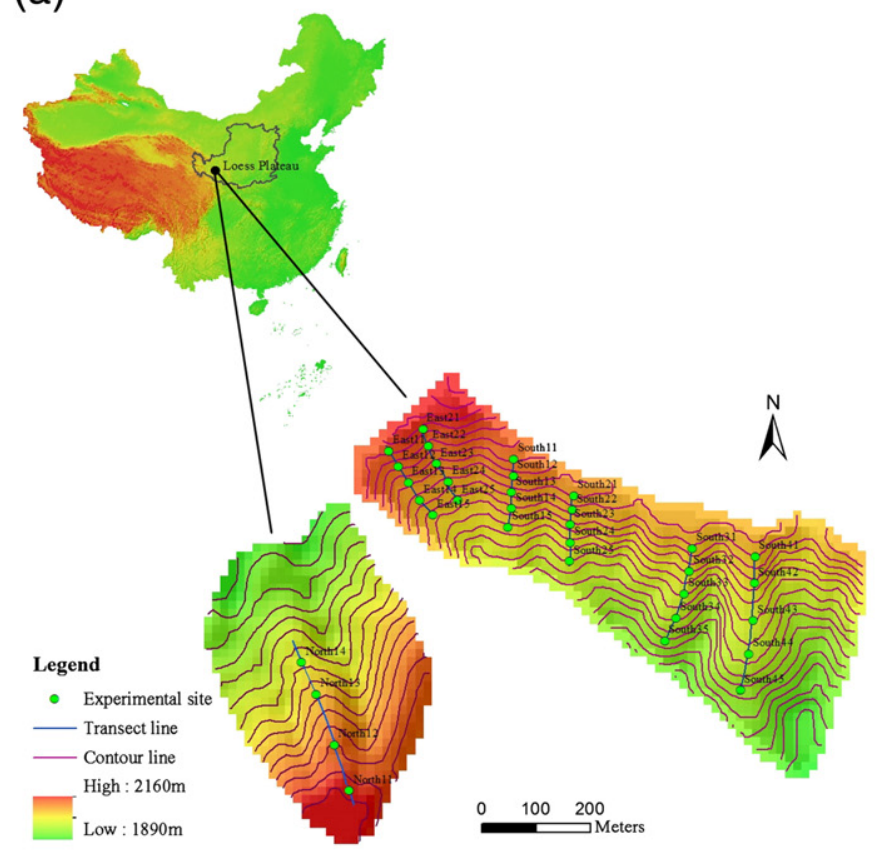

(b)

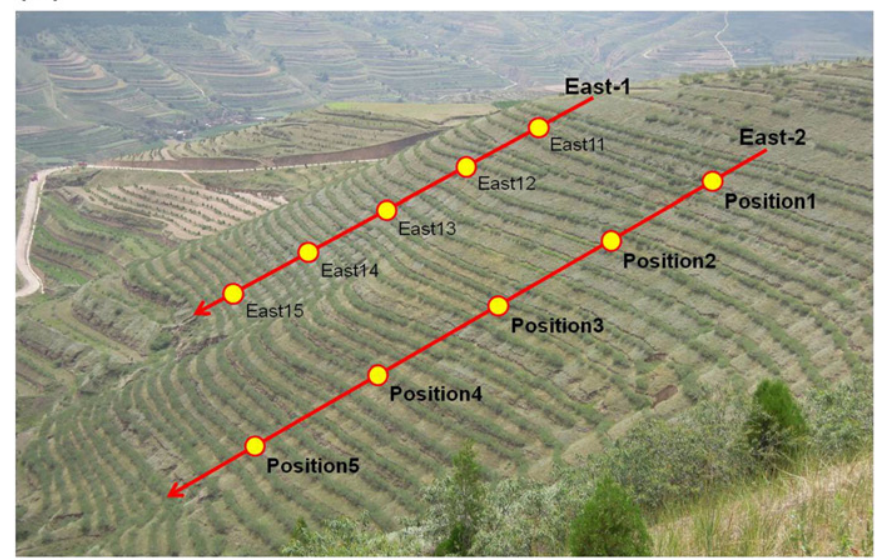

(c)

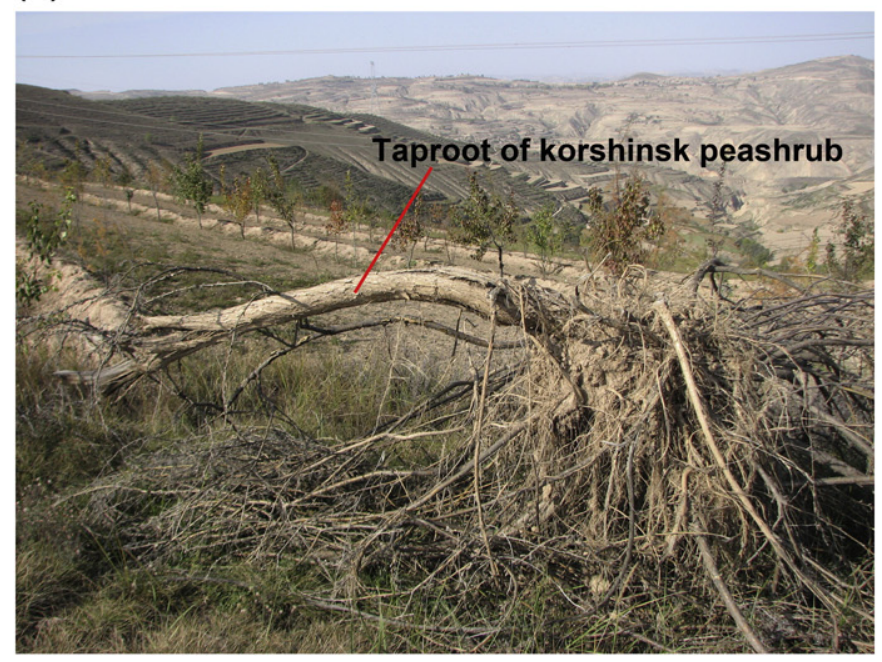

Fig. 1. Location of the study area and experimental sites. (a) Location of the study area in China and experimental sites on hillslopes. (b) Photo of hillslopes East-1 and East-2. (c) Photo of the taproot of korshinsk peashrub. canopy width (measured parallel to the contour lines) in a $20 \mathrm{~m} \times 20 \mathrm{~m}$ quadrat were recorded. We did not attempt to calculate biomass directly, due to the lack of reliable allometric equations for the plant architecture of korshinsk peashrub in this area. Instead, we used the mean height and the calculated canopy volume (equal to canopy length multiplied by canopy width) as proxies for the mean biomass of plots. Species composition, total herbaceous coverage, plant height, and biomass of the understory were also measured. Basic descriptions of each experimental site are given in Table 1.

\subsection{Statistical methods}

The basic statistics mean and standard deviation (S.D.) were calculated for each experimental site. One-way ANOVA was used to assess the contribution of different slope positions to the overall variation in soil moisture. Correlation analyses were conducted to quantify the strength of the association between SMC and environmental factors (topographic factors and vegetation attributes). SPSS $®$ (Version 18.0) was used for all statistical analyses. Canonical correspondence analysis (CCA), a constrained ordination technique, was used to identify specific environmental variables at different layers and was performed using the program CANOCO version 4.5. The following environmental variables, which showed significant correlations with SMC, were included in the CCA: altitude, slope aspect, planting density, TWI, canopy length and canopy width.

\section{Results}

\subsection{Vertical distributions of SMC at the hillslope scale}

The SMC in 0-1 m layers demonstrated relatively higher values than in deeper layers due to water replenishment through rainfall (Fig. 2). Generally, in all hillslopes SMC below shallow soil layers ( $0-1 \mathrm{~m})$ increased with soil depth. Different with shallow soil layers, obvious differences in SMC between different slope positions were found in deep layers. However, the vertical patterns for SMC measured over the five different positions on each hillslope were different between hillslopes (Fig. 2).

\subsection{SMC variations at different slope positions}

The differences in SMC0-1 between different slope positions on each hillslope were not obvious. However, a general trend of increasing shallow-layer SMC from the upper to the bottom position was found, with the exception of hillslope East-1 (Fig. 3a). This indicated that SMC generally increased along the direction of flow in shallow soil layers.

No obvious trend between slope positions was found for SMC1-2 (Fig. 3b). For example, the mean SMC at the upper-middle position $(0.057 \mathrm{~g} / \mathrm{g})$ on hillslope South- 1 was higher than at other positions $(0.050-0.051 \mathrm{~g} / \mathrm{g})$. However, the values of SMC at the middle position $(0.048 \mathrm{~g} / \mathrm{g})$ and middle-bottom position $(0.047 \mathrm{~g} / \mathrm{g})$ were clearly lower than at the upper and lower positions $(0.055-0.057 \mathrm{~g} / \mathrm{g})$ on hillslope South-3.

Interestingly, different with shallow soil layer, deep-layer SMC (below $2 \mathrm{~m}$ ) at bottom positions usually had relatively lower values than at upper positions. At upper positions, however, deep-layer SMC usually had relatively higher values than at the other positions (Fig. 3c, d). For example, the SMC at the upper-middle position on hillslope North-1 was significantly higher than at other positions at depths below $2 \mathrm{~m}$. The values for SMC at the upper position $(0.076 \mathrm{~g} / \mathrm{g})$ and upper-middle position $(0.076 \mathrm{~g} / \mathrm{g})$ on hillslope South-3 were significantly higher than at lower positions $(0.058-0.064 \mathrm{~g} / \mathrm{g}$, middle to bottom) at depths of 2-4 m. This result was different from those of studies focused on shallow layers (Qiu et al., 2001; Western et al., 2004). Normally, the SMC at the bottom location is much larger than 
Table 1

Basic descriptions of experimental sites.

\begin{tabular}{|c|c|c|c|c|c|c|c|c|c|c|}
\hline \multirow[t]{2}{*}{ Experimental site } & \multicolumn{4}{|c|}{ Topographic properties } & \multicolumn{6}{|c|}{ Vegetation attributes } \\
\hline & Altitude (m) & Slope aspect $\left({ }^{\circ}\right)$ & Slope gradient $\left({ }^{\circ}\right)$ & TWI & Mean height (m) & S.D. & Canopy length (m) & S.D. & Canopy width (m) & S.D. \\
\hline East11 & 2123 & 100 & 29 & 0.39 & 1.31 & 0.26 & 1.74 & 0.41 & 1.57 & 0.61 \\
\hline East12 & 2102 & 100 & 29 & 0.45 & 1.32 & 0.25 & 1.89 & 0.45 & 1.39 & 0.31 \\
\hline East13 & 2082 & 100 & 29 & 0.48 & 1.19 & 0.22 & 1.79 & 0.36 & 1.30 & 0.32 \\
\hline East14 & 2065 & 100 & 28 & 0.58 & 1.15 & 0.23 & 1.92 & 0.49 & 1.45 & 0.36 \\
\hline East15 & 2045 & 100 & 27 & 0.77 & 1.32 & 0.34 & 1.99 & 0.36 & 1.46 & 0.44 \\
\hline East21 & 2128 & 100 & 27 & 0.43 & 1.49 & 0.26 & 1.92 & 0.40 & 1.90 & 0.41 \\
\hline East22 & 2100 & 100 & 28 & 0.65 & 1.30 & 0.30 & 1.56 & 0.43 & 1.12 & 0.33 \\
\hline East23 & 2081 & 100 & 28 & 0.68 & 1.47 & 0.25 & 1.88 & 0.34 & 1.33 & 0.42 \\
\hline East24 & 2065 & 100 & 28 & 0.71 & 1.82 & 0.36 & 2.27 & 0.44 & 1.65 & 0.48 \\
\hline East25 & 2047 & 100 & 28 & 0.75 & 2.21 & 0.23 & 2.79 & 0.35 & 1.88 & 0.45 \\
\hline North11 & 2120 & 330 & 8 & 0.30 & 1.38 & 0.41 & 1.69 & 0.36 & 1.38 & 0.35 \\
\hline North12 & 2100 & 330 & 35 & 0.32 & 1.05 & 0.23 & 1.07 & 0.24 & 0.98 & 0.22 \\
\hline North13 & 2066 & 330 & 27 & 0.43 & 1.12 & 0.41 & 1.54 & 0.35 & 1.21 & 0.38 \\
\hline North14 & 2045 & 330 & 24 & 0.50 & 1.58 & 0.40 & 1.65 & 0.29 & 1.58 & 0.21 \\
\hline South11 & 2103 & 180 & 30 & 0.45 & 1.16 & 0.32 & 1.75 & 0.44 & 1.27 & 0.32 \\
\hline South12 & 2086 & 180 & 30 & 0.48 & 1.17 & 0.28 & 1.81 & 0.37 & 1.28 & 0.27 \\
\hline South13 & 2067 & 180 & 30 & 0.49 & 1.17 & 0.32 & 1.75 & 0.48 & 1.24 & 0.34 \\
\hline South14 & 2049 & 180 & 30 & 0.43 & 1.15 & 0.35 & 1.80 & 0.45 & 1.34 & 0.44 \\
\hline South15 & 2022 & 180 & 30 & 0.49 & 1.35 & 0.27 & 2.04 & 0.37 & 1.42 & 0.34 \\
\hline South21 & 2066 & 180 & 30 & 0.27 & 0.95 & 0.27 & 1.63 & 0.44 & 1.33 & 0.38 \\
\hline South22 & 2058 & 180 & 32 & 0.31 & 1.08 & 0.33 & 1.52 & 0.39 & 1.23 & 0.44 \\
\hline South23 & 2038 & 180 & 32 & 0.32 & 1.19 & 0.12 & 1.94 & 0.29 & 1.41 & 0.21 \\
\hline South24 & 2020 & 180 & 32 & 0.43 & 1.21 & 0.32 & 1.92 & 0.41 & 1.57 & 0.43 \\
\hline South25 & 1998 & 180 & 32 & 0.48 & 1.18 & 0.28 & 2.02 & 0.41 & 1.57 & 0.44 \\
\hline South31 & 2048 & 180 & 32 & 0.31 & 1.05 & 0.35 & 1.55 & 0.51 & 1.27 & 0.44 \\
\hline South32 & 2020 & 180 & 32 & 0.35 & 1.13 & 0.27 & 1.69 & 0.41 & 1.34 & 0.28 \\
\hline South33 & 2000 & 180 & 31 & 0.37 & 1.19 & 0.29 & 1.83 & 0.43 & 1.36 & 0.36 \\
\hline South34 & 1980 & 180 & 31 & 0.42 & 1.16 & 0.38 & 1.77 & 0.42 & 1.38 & 0.43 \\
\hline South35 & 1954 & 180 & 31 & 0.45 & 0.95 & 0.37 & 1.33 & 0.37 & 1.10 & 0.46 \\
\hline South41 & 2051 & 180 & 30 & 0.30 & 1.20 & 0.32 & 1.78 & 0.48 & 1.40 & 0.35 \\
\hline South42 & 2030 & 180 & 30 & 0.36 & 1.07 & 0.33 & 1.68 & 0.38 & 1.33 & 0.45 \\
\hline South43 & 2000 & 180 & 12 & 0.48 & 1.16 & 0.25 & 1.67 & 0.46 & 1.34 & 0.34 \\
\hline South44 & 1985 & 180 & 30 & 0.37 & 1.18 & 0.26 & 1.64 & 0.41 & 1.33 & 0.34 \\
\hline South45 & 1952 & 180 & 30 & 0.43 & 1.33 & 0.31 & 2.10 & 0.56 & 1.53 & 0.48 \\
\hline
\end{tabular}

Note: TWI represents topographic wetness index; the canopy length was measured perpendicularly to the contour and the canopy width was measured along with contour.

at upper positions because the contributing area is larger, thus the lower position would have a higher SMC because of soil drainage from the upper section of the hillslope (Western et al., 1999). However, unlike spatial patterns for shallow-layer SMC, deep-layer SMC decreased along the direction of flow from the upper to the bottom positions (Fig. $3 c$ and $d$ ).

Long-term 0-2 m layer soil moisture observations (2009-2012) also showed that temporally averaged SMC0-1 increased from the upper to the bottom positions (Fig. 4a). For example, the temporally averaged SMC on hillslope North-1 was $0.064 \mathrm{~g} / \mathrm{g}$ at the upper position, increasing to $0.068 \mathrm{~g} / \mathrm{g}$ at the middle position and $0.076 \mathrm{~g} / \mathrm{g}$ at the bottom position. Increasing trends were also obvious for hillslopes East-2 and South-2. However, no clear increasing or decreasing trend could be found for temporally averaged SMC1-2 along hillslopes from the upper position to the bottom position (Fig. 4b). Spatial variation in SMC1-2 was more complex than that for shallow layers.

\subsection{Correlations between SMC and environmental factors}

The correlation coefficient for SMC0-1 and altitude was 0.359 $(p<0.05)$. Although this value was low, it could still indicate that bottom positions usually have a relatively higher SMC than upper positions. The correlation coefficient for shallow SMC and slope gradient, however, indicated that gentle slopes usually have a relatively higher SMC. This was consistent with previous studies (Cantón et al., 2004; Western et al., 2004). Correlation analysis for SMC0-1 and TWI $(0.595, p<0.01)$ indicated that topographic factors were positively correlated for shallow-layer SMC.

A statistically significant negative relationship between TWI and SMC was found in deep layers (Table 2). The correlation coefficients for TWI with SMC2-4 and SMC4-6, respectively, were -0.595 and $-0.539(p<0.01)$. Correlation analysis for altitude and deep-layer SMC gave a similar result. The effect of topographic factors (altitude, aspect, gradient, and TWI) on shallow-layer SMC in this study was consistent with that found in previous studies (Ali et al., 2010; Cantón et al., 2004; Qiu et al., 2001). However, correlation analysis for topographic factors and deep-layer SMC was different from the spatial patterns of shallow-layer SMC. The vegetation structure indices (mean height and canopy volume) were positively correlated with SMC in 0-1 m layers, but negatively correlated in 2-6 m layers (Table 2). The values of the vegetation structure indices increased from upper positions to bottom positions (Table 1) and were positively correlated with TWI. Correlation analysis showed that plants with large vegetation structure indices (high biomass) were associated with relatively lower deep-layer SMC values.

The results of correlation analysis for SMC and environmental variables were also supported by CCA, as shown in Fig. 5. The four SMC layers were arranged along the first axis on a CCA ordination biplot. The TWI and vegetation structure attributes (mean height, canopy volume) were the dominant environmental variables correlating with this axis. The plot indicated that SMC at $0-1 \mathrm{~m}$ was significantly correlated with TWI and biomass. However, SMC in 2-4 $\mathrm{m}$ and 4-6 m layers were negatively correlated with TWI and biomass.

\section{Discussion}

\subsection{Vertical variation in SMC in the semi-arid Loess Plateau}

In semi-arid regions, SMC varies seasonally in shallow layers depending on annual precipitation. Compared with topsoil, temporal dynamics in deeper soil layers were diminished due to lower infiltration of precipitation and to root water uptake (Rosenbaum et al., 2012). Due 
(a)

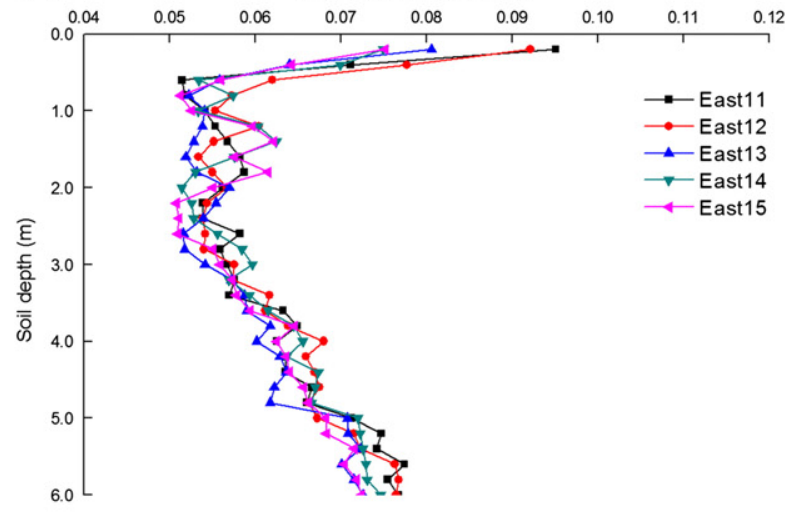

(c)

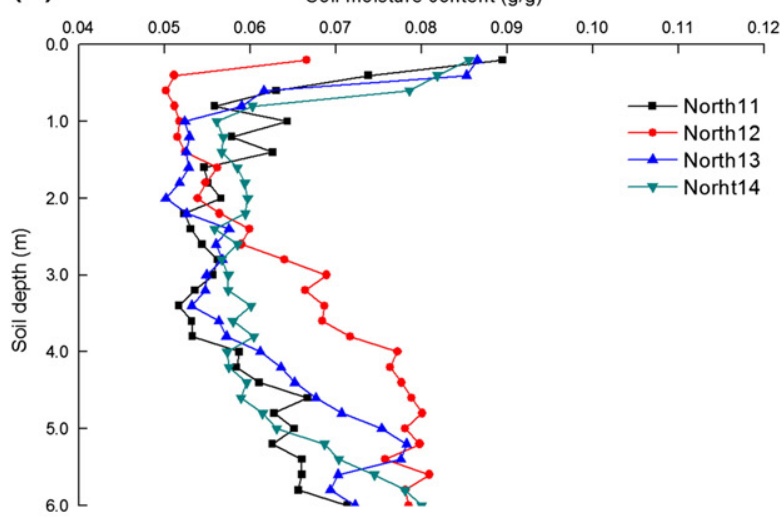

(e)

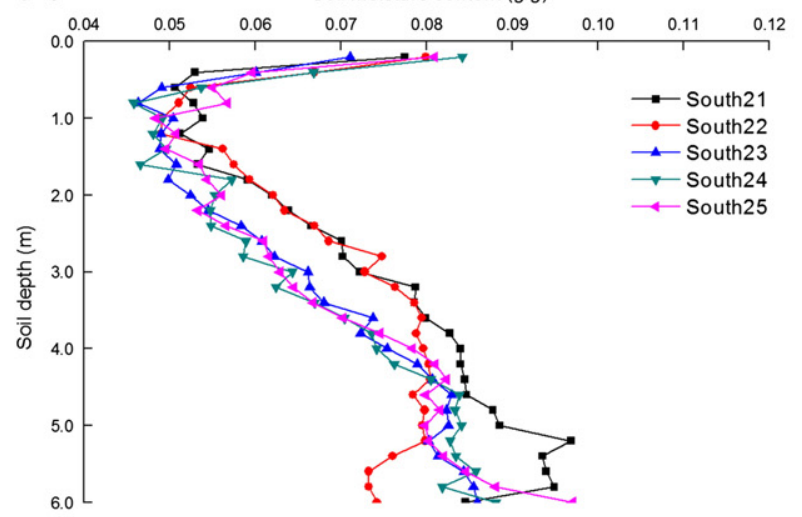

(b)

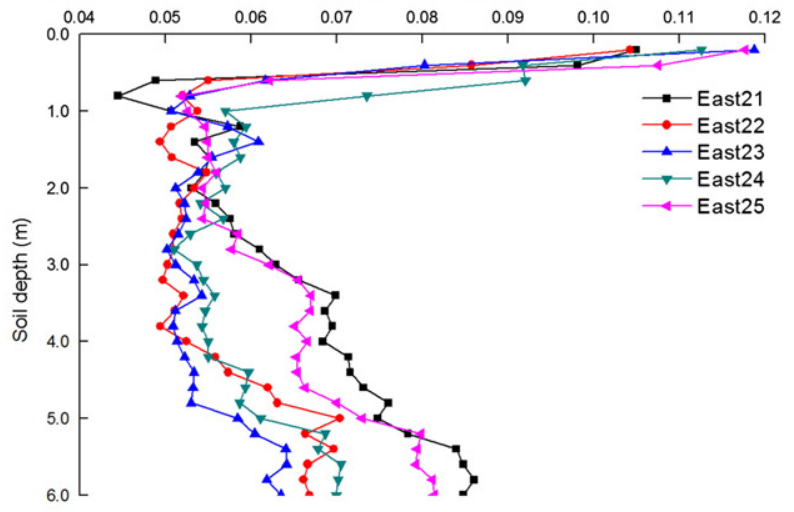

(d)

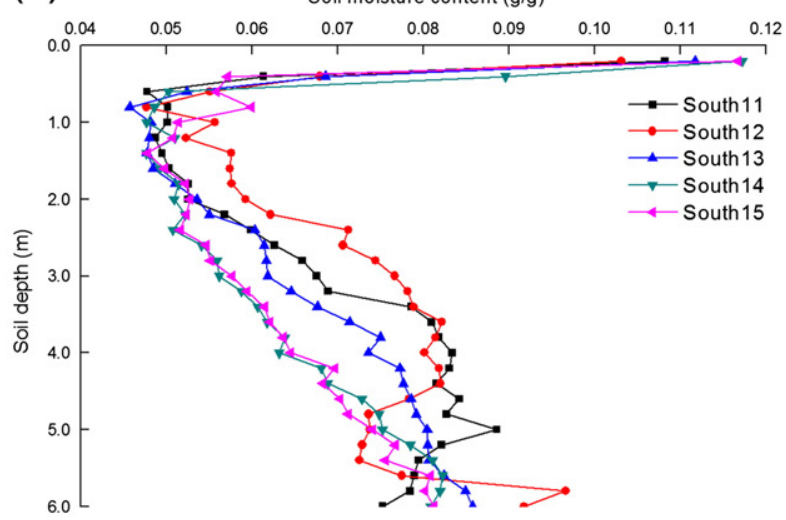

(f)

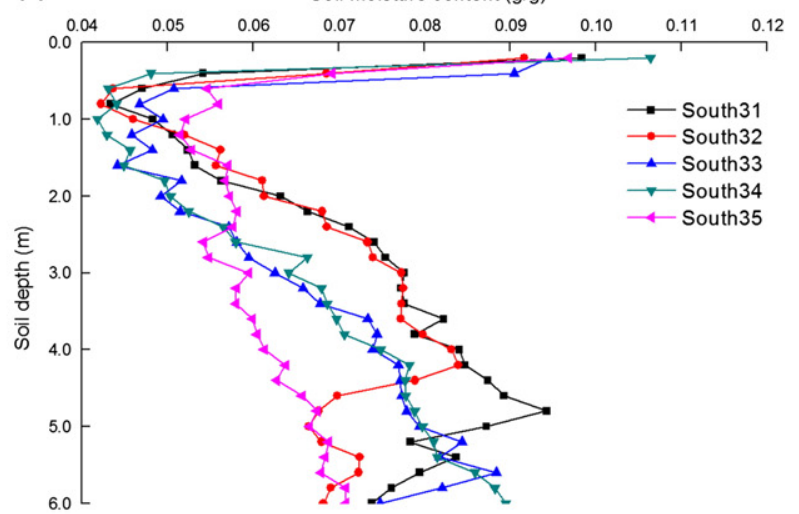

(g)

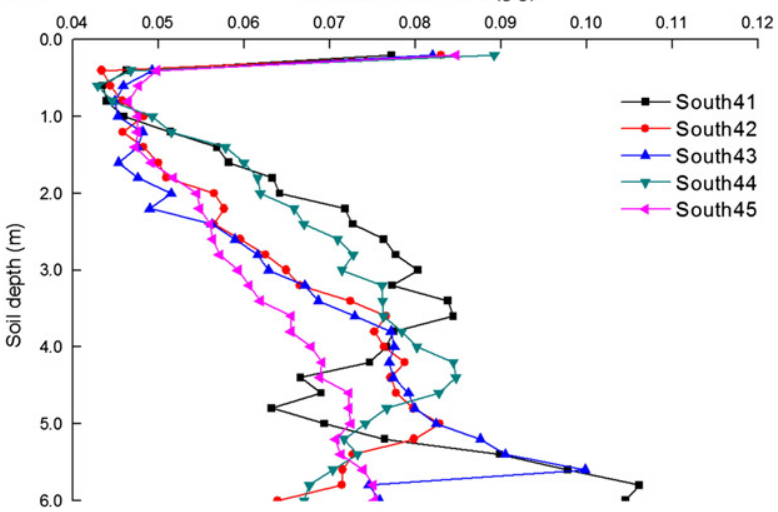

Fig. 2. Vertical distributions of soil moisture content on different hillslopes. 
(a) Layer: 0-1 m

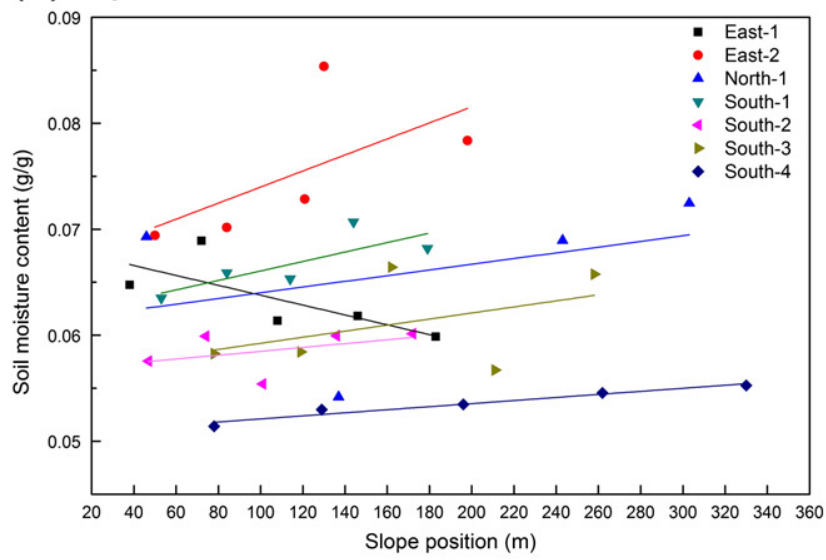

(c) Layer: 2-4 m

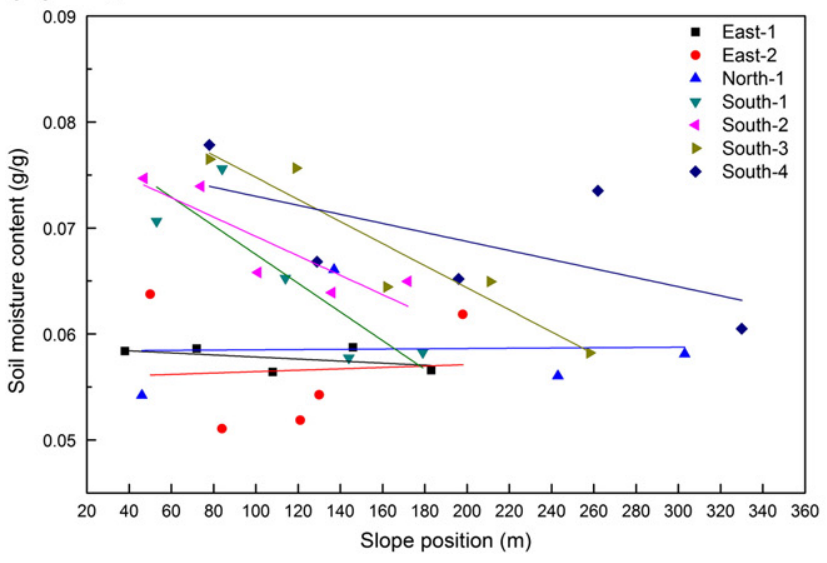

(b) Layer: 1-2 m

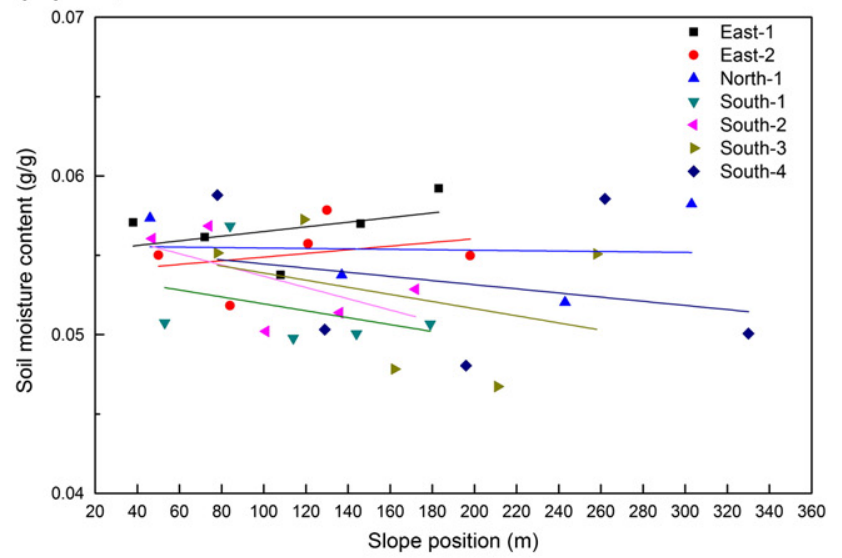

(d) Layer: 4-6 m

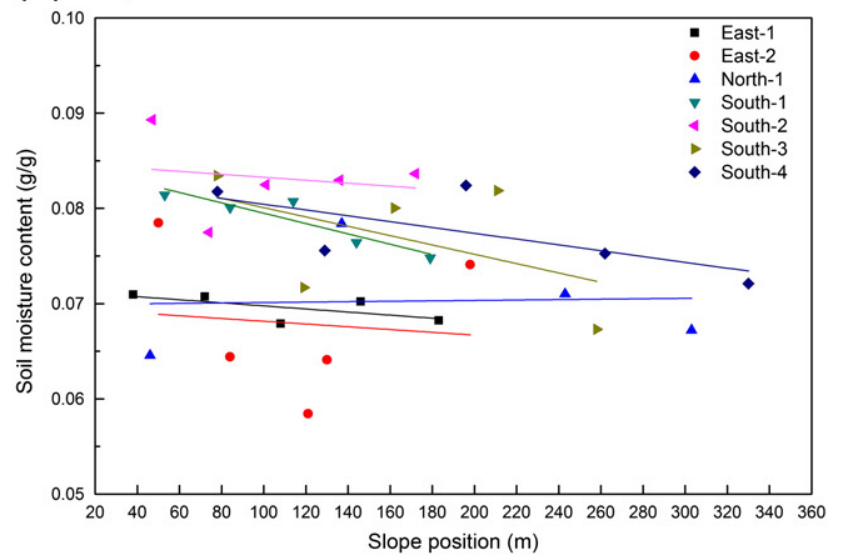

Fig. 3. Relationship between soil moisture content and slope positions. Note: The line is a linear-fit curve.

to the thickness of the loess on the Loess Plateau, vertical distribution and temporal variations in deep-layer SMC differ from those in shallow-layer SMC (Chen et al., 2008b; Wang et al., 2009). In lands with introduced vegetation, the SMC below the rainfall infiltration depth was relatively more stable during different seasons than in shallow layers (Cheng et al., 2009; Yang et al., 2012a). For example, Cheng et al. (2005) and Wang et al. (2010) analyzed the seasonal changes in SMC and found the SMC below $1 \mathrm{~m}$ was not greatly affected by rainfall and root water uptake and remained relatively stable before, during and after the rainy season. Cheng et al. (2009) and Gao and Shao (2012) also found that SMC in deep soil layers underwent relatively small temporal changes by soil moisture monitoring at the depth of 0-6 m. Wang et al. (2009) even found no significant differences in deep soil moisture (below $2 \mathrm{~m}$ ) over 6 years of observations in the Loess Plateau. In the study area, the annual rainfall infiltration depth barely reaches $1 \mathrm{~m}$ and SMC below this depth remained relatively temporal stable according to long-term soil moisture observations in the field (Yang et al., 2014). The korshinsk peashrub plants have been growing for nearly 30 years and this area has become a mature shrubland. Deep soil moisture in mature shrubland and forestland is generally temporally stable (Wang et al., 2009; Chen et al., 2008a, 2010). This study focused on the deep soil moisture conditions, which can be considered as a stable result of introduced vegetation restoration. The deep-layer SMC data observed in the late growing season can thus be used to reflect the stable soil moisture conditions in deep soil profiles. Further studies based on location monitoring and long-term monitoring are still required to provide more convincing evidence on temporal stability in deep soil moisture.
The information on root vertical distribution is important for understanding soil moisture dynamics in semi-arid ecosystems. The korshinsk peashrub has a strong taproot in loess soils (Fig. 1c) and the root system can extend to a depth of $10 \mathrm{~m}$ (Cheng et al., 2005). While no root distribution data are available, previous studies have accumulated abundant information on this issue which can contribute to explaining the effect of root distribution on vertical variation in SMC. Wang et al. (2010) measured root length density, root weight density, root surface area density, and root average diameter, and found that the roots of the korshinsk peashrub can extend through 0-6 m. Cheng et al. (2009) found that most of the fine roots of the korshinsk peashrub (70\%) were distributed in the uppermost $1 \mathrm{~m}$; however, they also found that this plant tended to extend deeper roots in loess soils; the depth of root uptake for this plant can extend to $10 \mathrm{~m}$ or more (Chen et al., 2008a, 2008b; Cheng et al., 2005). Thus, the shallow layer is the main layer providing soil water for plant growth, and the SMC in this layer changes with rainfall and root water uptake. Soil water stored in deep layers is a reliable water source for plant growth in the initial years, and the SMC in deep layers becomes temporally stable after years of growth.

\subsection{Different spatial patterns for SMC between shallow and deep layers}

Topographic factors play important roles in soil moisture in certain conditions (Venkatesh et al., 2011). Generally, the spatial distribution of soil moisture at the hillslope scale is that SMC increases along the direction of surface flow from the top to the bottom of the hillslope. This spatial distribution pattern has been proven in many previous 
(a) Layer: 0-1 m

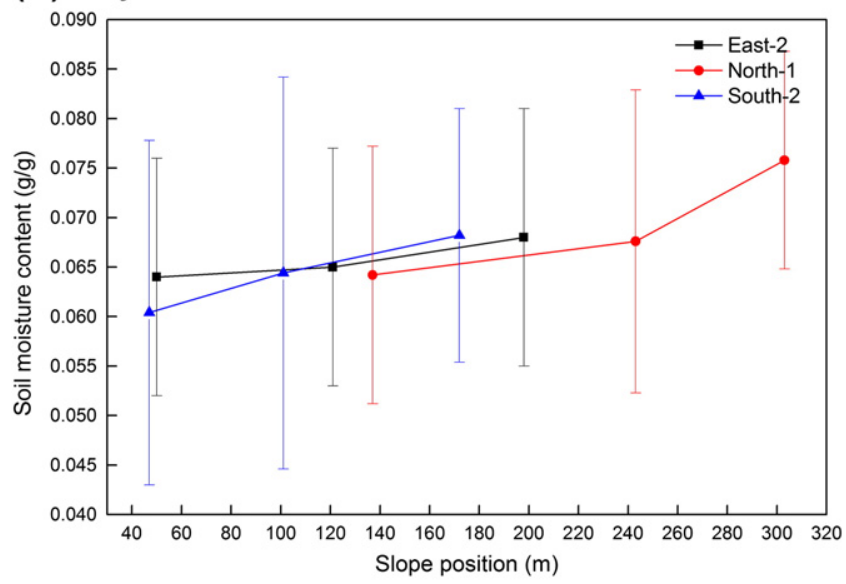

(b) Layer: 1-2 m

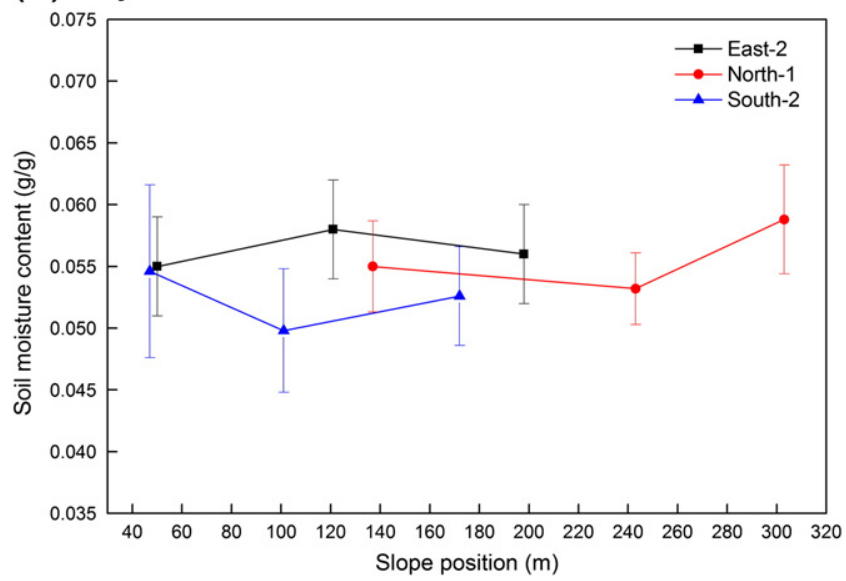

Fig. 4. Relationship between long-term observed soil moisture content and slope position. Note: temporally averaged soil moisture values were means of long-term soil moisture observations (2009-2012, $n=39$ ). The error bars indicate the standard deviation of the soil moisture content for 39 observations.

studies (Legates et al., 2011; Western and Blöschl, 1999; Crave and Gascuel-Odoux, 1997) and using topography-based models (Cantón et al., 2004; Western et al., 1999). In the Loess Plateau, spatial variations in SMC in shallow layers that are affected by topographic factors also correspond to this pattern (Qiu et al., 2001; Zhu and Shao, 2008). The results of single and long-term soil moisture observations in this study showed that shallow-layer SMC was significantly positively correlated with altitude and TWI, and negatively correlated with slope gradient

Table 2

Correlation analysis of soil moisture content and environmental factors.

\begin{tabular}{|c|c|c|c|c|c|c|}
\hline \multirow[t]{2}{*}{ Soil depth } & \multicolumn{4}{|c|}{ Topographic factors } & \multicolumn{2}{|c|}{ Vegetation attributes } \\
\hline & Altitude & $\begin{array}{l}\text { Slope } \\
\text { aspect }\end{array}$ & $\begin{array}{l}\text { Slope } \\
\text { gradient }\end{array}$ & TWI & $\begin{array}{l}\text { Mean } \\
\text { height }\end{array}$ & $\begin{array}{l}\text { Canopy } \\
\text { volume }\end{array}$ \\
\hline $0-1 \mathrm{~m}$ & $0.359^{*}$ & -0.196 & -0.255 & $0.595^{* *}$ & $0.695^{* *}$ & $0.565^{* *}$ \\
\hline p Value & 0.037 & 0.266 & 0.105 & 0.000 & 0.000 & 0.001 \\
\hline $1-2 \mathrm{~m}$ & $0.344^{*}$ & -0.106 & -0.084 & 0.121 & 0.224 & 0.146 \\
\hline p Value & 0.046 & 0.551 & 0.638 & 0.496 & 0.202 & 0.409 \\
\hline $2-4 \mathrm{~m}$ & -0.172 & 0.156 & $0.439^{* *}$ & $-0.595^{* *}$ & $-0.409 *$ & -0.252 \\
\hline p Value & 0.332 & 0.379 & 0.009 & 0.000 & 0.016 & 0.151 \\
\hline $4-6 \mathrm{~m}$ & -0.204 & 0.165 & $0.386^{*}$ & $-0.539_{* * *}$ & $-0.410^{*}$ & -0.185 \\
\hline p Value & 0.248 & 0.351 & 0.024 & 0.001 & 0.016 & 0.294 \\
\hline
\end{tabular}

Note: TWI represents topographic wetness index; the canopy volume was canopy length multiplied by canopy width.

* Significant at the 0.05 level.

** Significant at the 0.01 level.

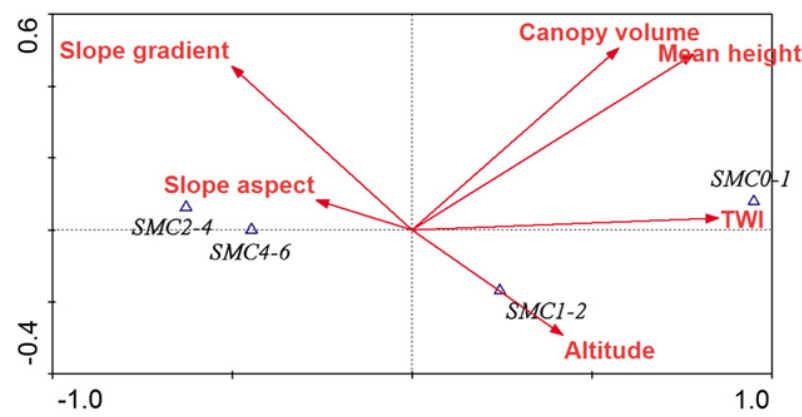

Fig. 5. Canonical correspondence analysis ordination biplot showing the relationship between depth-averaged soil moisture content and environmental factors.

(Table 2; Figs. 3a and 4a). The results for spatial variation in shallowlayer SMC were consistent with those of previous studies based on long-term observations (Meerveld and McDonnell, 2006; Penna et al., 2009; Zhu et al., 2014). Comparing our results with those published for other semi-arid ecosystems, we found that spatial variations in shallow-layer SMC in our study corresponded to the general spatial patterns and the results of previous studies.

However, spatial variations in deep-layer SMC were significantly different from patterns in shallow layers. The measured data and statistical analysis of our study provided evidence that slope position/TWI may only affect SMC in shallow soil layers but not deep layers (Fig. 3). The values for SMC in 1-2 m layers were not significantly different between the five slope positions and there was no significant correlation with topographic factors and vegetation attributes (Table 2, Figs. 3b and 5). Compared with shallow-layer SMC, deep-layer SMC values generally decreased with lower slope position (Fig. 3). Correlation analysis and CCA for deep-layer SMC and topographic factors indicated that the spatial pattern of deep-layer SMC at the hillslope scale was different from that in shallow layers. This result was also different with the spatial pattern in deep SMC covered with natural vegetation. Previous studies concerning on spatial variation in deep-layer SMC provided the evidence that deep SMC in natural vegetation increased from top to bottom at the hillslope scale. For instance, He et al. (2002) found the SMC increased from upper position to bottom position in natural native grassland by field observation in depth of $0-4 \mathrm{~m}$ in the Loess Plateau. Yang et al. (2012b) also found that the spatial pattern of deep-layer SMC in natural vegetation corresponded to the general spatial distribution patterns, but was different for introduced vegetation types. The result in this study reflected the different spatial distribution of deep-layer SMC to those of shallow-layer SMC at the hillslope scale under the influence of introduced vegetation restoration. This result also indicated that TWI cannot simply be used as an evaluating indicator for deep-layer SMC, according to correlation analysis (Table 2) and CCA (Fig. 5).

\subsection{The determining role of vegetation on spatial variation in deep-layer SMC}

Vegetation has a significant influence on soil moisture and its spatial-temporal variation. In the Loess Plateau, re-vegetation with highly productive plants is the major possible reason for the severe soil desiccation found in deep layers (Yang et al., 2014). Vegetation restoration with a high planting density not only decreases deep-layer SMC, but also changes the spatial variations of SMC in shallow and deep layers. In this study, taking hillslope North-1 as an example, SMC0-1 values at positions 1 and 4 were relatively higher than at the other positions and the SMC4-6 values at positions 1 and 4 were significantly lower than at positions 2 and 3. This may be explained by vegetation structure attributes. At position 1 (mean height $1.38 \mathrm{~m}$, canopy volume $1.69 \times 1.38 \mathrm{~m}$ ) and position 4 (mean height $1.58 \mathrm{~m}$, canopy volume $1.65 \times 1.58 \mathrm{~m}$ ), vegetation structure attributes were significantly better than at positions 2 (mean height $1.05 \mathrm{~m}$, canopy 
volume $1.07 \times 0.98 \mathrm{~m}$ ) and 3 (mean height $1.12 \mathrm{~m}$, canopy volume $1.54 \times 1.21 \mathrm{~m}$ ). Owing to the less developed root system, poor growth of korshinsk peashrub at positions 2 and 3 will lead to a lower consumption of soil water, particularly deep soil water. Another clear example was the spatial patterns in SMC on hillslope South-2. The deep-layer SMC values at positions 1 and 2 on this hillslope at the depth of 2-6 m were significantly higher than at the other three positions (Fig. 2e). The growth of korshinsk peashrub at positions 1 (mean height $0.95 \mathrm{~m}$, canopy volume $1.63 \times 1.33 \mathrm{~m}$ ) and 2 (mean height $1.08 \mathrm{~m}$, canopy volume $1.52 \times 1.23 \mathrm{~m}$ ) was poorer than at positions 3,4 and 5 (mean height $1.18-1.21 \mathrm{~m}$, canopy volume $11.92-2.02 \mathrm{~m}$, canopy volume 2 1.41-1.57 m). The relatively better growth of korshinsk peashrub at positions 3, 4 and 5 may lead to greater water uptake from the deep soil by plants of larger structure, resulting in lower deep-layer SMC. Correlation analysis for deep-layer SMC and vegetation structure attributes provided an evidence for the dynamic role of biomass on soil moisture variation (Table 2; Fig. 5). This could also explain why deep-layer SMC on upper positions was significantly higher than at other lower positions. Biomass may be considered as the main influencing factor in determining spatial distribution in deep-layer SMC at the hillslope scale.

The negative correlations of aboveground vegetation attributes with deep-layer SMC are related to patterns of water uptake by plants, as also proved by Ferreira et al. (2007) in Brazilian savanna ecosystems. To obtain a more reliable and precise picture of this issue, other physical and biological aspects that influence soil moisture dynamics should be taken into account. For example, information on root distribution is very important for understanding hydrologic processes in plant-water systems. Direct evidence such as root distribution and root dynamics for different vegetation types would greatly strengthen the research conclusions. These direct evidences may provide more close correlations between soil moisture and vegetation patterns. Furthermore, the gravimetric measurement of moisture is limited in terms of reflecting interactions between soil moisture and plants. Volumetric moisture content would be better for assessing plant water potential. Because deep soil moisture in the Loess Plateau is difficult to measure by using the TDR system, in this study we used gravimetric SMC to represent the soil moisture conditions in deep soil layers.

The introduced vegetation can alter the contribution of topography to specific soil moisture variations. This may occur when relatively high SMC at bottom positions in the initial growth period can lead to strong growth (high biomass) due to high available water source. However, the relatively better growth of introduced vegetation at bottom positions results in consumption of more deep soil water than that at upper positions. The relatively lower deep-layer SMC after years of growth results from a relatively high soil water consumption. The effects of introduced vegetation on the dynamics of deep soil moisture are thus significant and important. However, further studies are still required to identify the water replenishment and cycling process by continuous soil moisture monitoring. Because the effect of topographic factors on spatial variation in deep SMC has been altered by introduced vegetation restoration, it may not be possible simply to use topography-based models such as the TWI to evaluate deep soil moisture conditions without considering vegetation features.

\section{Conclusions}

Based on comparing SMC at different slope positions together with consideration of soil depth and vegetation attributes, the results showed that the TWI was positively correlated with shallow-layer SMC and negatively correlated with deep-layer SMC, and a negative relationship between biomass and SMC was found in deep soil layers. The spatial distribution of soil moisture on hillslope scale was different in deep and shallow soil layers. Topography may affect soil moisture in shallow layers but deep layers in re-vegetation areas. The planted vegetation may change the spatial patterns of deep-layer SMC at the hillslope scale due to differences in water consumption, which has a relationship with biomass. Vegetation with a relatively higher biomass usually has a relatively lower deep-layer SMC. Thus, the biomass is considered to be the determining factor regarding spatial distribution of deep soil moisture.

\section{Acknowledgments}

We acknowledge the considerable assistance of Ziting Wang, Xianbin Zhao, and Baoru Mo with field sampling and laboratory procedures. This study was supported by the National Natural Science Foundation of China (41390462, 41401209, 41371123). We thank the two anonymous reviewers for their constructive comments and suggestions.

\section{References}

Ali, G.A., Roy, A.G., Legendre, P., 2010. Spatial relationships between soil moisture patterns and topographic variables at multiple scales in a humid temperate forested catchment. Water Resour. Res. 46, W10526. http://dx.doi.org/10.1029/2009WR008804.

Cantón, Y., Solé-Benet, A., Domingo, F., 2004. Temporal and spatial patterns of soil moisture in semiarid badlands of SE Spain. J. Hydrol. 285, 199-214.

Chen, L., Wei, W., Fu, B., Lv, Y., 2007. Soil and water conservation on the loess plateau in China: review and perspective. Prog. Phys. Geogr. 31 (4), 389-403.

Chen, H., Shao, M., Li, Y., 2008a. Soil desiccation in the Loess Plateau of China. Geoderma 143, 91-100.

Chen, H., Shao, M., Li, Y., 2008b. The characteristics of soil water cycle and water balance on steep grassland under natural and simulated rainfall conditions in the Loess Plateau of China. J. Hydrol. 360, 242-251.

Chen, L., Wang, J., Wei, W., Fu, B., Wu, D., 2010. Effects of landscape restoration on soil water storage and water use in the Loess Plateau Region, China. For. Ecol. Manag. 259, 1291-1298.

Cheng, J., Wan, H., Wang, J., Yong, S., 2005. Growth of Caragana korshinskii and depletion process of soil water in semi-arid region. Sci. Silvae Sin. 41 (1), 37-41 (In Chinese).

Cheng X. Huang M. Shao, M. Warrington, D.N. 2009. A comparison of fine root distribution and water consumption of mature Caragana korshinkii Kom grown in two soils in a semiarid region, China. Plant Soil 315, 149-161.

Crave, A., Gascuel-Odoux, C., 1997. The influence of topography on the time and space distribution of soil surface water content. Hydrol. Process. 11, 203-210.

Engelbrecht, B.M.J., Comita, L.S., Condit, R., Kursar, T.A., Tyree, M.T., Turner, B.L., Hubbell, S.P., 2007. Drought sensitivity shapes species distribution patterns in tropical forests. Nature 447, 80-82.

Ferreira, J.N., Bustamante, M., Garcia-Montiel, D.C., Caylor, K.K., Davidson, E.A., 2007. Spatial variation in vegetation structure coupled to plant available water determined by two-dimensional soil resistivity profiling in a Brazilian savanna. Oecologia 153, 417-430.

Gao, L., Shao, M., 2012. Temporal stability of soil water storage in diverse soil layers. Catena 95, 24-32.

Gómez-Plaza, A., Alvarez-Rogel, J., Albaladejo, J., Castillo, V.M., 2000. Spatial patterns and temporal stability of soil moisture across a range of scales in a semi-arid environment. Hydrol. Process. 14, 1261-1277.

He, F., Huang, M., Dang, T., 2002. Soil water distribution characteristics in Wangdonggou watershed in Gully Region of Loess Plateau. Bull. Soil Water Conserv. 22 (4), 6-9 (In Chinese)

Hebrard, O., Voltz, M., Andrieux, P., Moussa, R., 2006. Spatio-temporal distribution of soil surface moisture in a heterogeneously farmed Mediterranean catchment. J. Hydrol. 329, 110-121.

Ivanov, V.Y., Fatichi, S., Jenerete, G.D., Fspeleta, J.F., Troch, P.A., Huxman, T.E., 2010. Hysteresis of soil moisture spatial heterogeneity and the "homogenizing" effect of vegetation. Water Resour. Res. 46, W009521. http://dx.doi.org/10.1029/2009WR008611.

Jin, T.T., Fu, B.J., Liu, G.H., Wang, Z., 2011. Hydrologic feasibility of artificial forestation in the semi-arid Loess Plateau of China. Hydrol. Earth Syst. Sci. 15, 2519-2530.

Legates, D.R., Mahmood, R., Levia, D.F., Deliberty, T.L., Quiring S.M., Houser, C., Nelson, F.E., 2011. Soil moisture: a central and unifying theme in physical geography. Prog. Phys. Geogr. 35 (1), 65-86.

Meerveld, H.J.T., McDonnell, J.J., 2006. On the interrelations between topography, soil depth, soil moisture, transpiration rates and species distribution at the hillslope scale. Adv. Water Resour. 29, 293-310.

Penna, D., Borga, M., Norbiato, D., Fontana, G.D., 2009. Hillslope scale soil moisture variability in a steep alpine terrain. J. Hydrol. 364, 311-327.

Porporato, A., D'Odorico, P., Laio, F., Ridolfi, L., Rodriguez-Iturbe, I., 2002. Ecohydrology of water-controlled ecosystems. Adv. Water Resour. 25, 1335-1348.

Price, K., 2011. Effects of watershed topography, soils, land use, and climate on baseflow hydrology in humid regions: a review. Prog. Phys. Geogr. 35 (4), 465-492.

Qiu, Y., Fu, B., Wang, J., Chen, L., 2001. Spatial variability of soil moisture content and its relation to environmental indices in a semi-arid gully catchment of the Loess Plateau, China. J. Arid Environ. 49, 723-750.

Rosenbaum, U., Bogena, H.R., Herbst, M., Huisman, J.A., Peterson, T.J., Weuthen, A., Western, A.W., Vereecken, H., 2012. Seasonal and event dynamics of spatial soil moisture patterns at the small catchment scale. Water Resour. Res. 48, W10544. http://dx. doi.org/10.1029/2011WR011518.

Sanchez-Mejia, Z., Papuga, S., Swetish, J., Leeuwen, W., Szutu, D., Hartfield, K., 2014. Quantifying the influence of deep soil moisture on ecosystem albedo: the role of vegetation. Water Resour. Res. 50, 4038-4053. 
Sun, G., Zhou, G., Zhang, Z., Wei, X., McNulty, S.G., James, M.V., 2006. Potential water yield reduction due to forestation across China. J. Hydrol. 328, 548-558.

Venkatesh, B., Lakshman, N., Purandara, B.K., Reddy, V.B., 2011. Analysis of observed soil moisture patterns under different land covers in Western Ghats, India. J. Hydrol. 397, 281-294.

Vivoni, E.R., Rinehart, A.J., Méndez-Barroso, L.A., Aragón, C.A., Bisht, G., Cardenas, M.B., Engle, E., Forman, B.A., Frisbee, M.D., Gutiérrez-Jurado, H.A., Hong, S., Mahmood, T.H., Tai, K., Wyckoff, R.L., 2008. Vegetation controls on soil moisture distribution in the Valles Caldera, New Mexico, during the North American monsoon. Ecohydrology 1, 225-238.

Wang, Z., Liu, B., Zhang, Y., 2009. Soil moisture of different vegetation types on the Loess Plateau. J. Geogr. Sci. 19 (6), 707-718.

Wang, Y., Shao, M., Shao, H., 2010. A preliminary investigation of the dynamic characteristics of dried soil layers on the Loess Plateau of China. J. Hydrol. 381, 9-17.

Western, A.W., Blöschl, G., 1999. On the spatial scaling of soil moisture. J. Hydrol. 217. 203-224.

Western, A.W., Grayson, R.B., Bloschl, G., Willgoose, G.R., McMahon, T.A., 1999. Observed spatial organization of soil moisture and its relation to terrain indices. Water Resour. Res. 35 (3), 797-810.
Western, A.W., Zhou, S.L., Grayson, R.B., McMahon, T.A., Blöschl, G., Wilson, D.J., 2004. Spatial correlation of soil moisture in small catchments and its relationship to dominant spatial hydrological processes. J. Hydrol. 286, 113-134.

Yang, L., Wei, W., Chen, L., Mo, B., 2012a. Response of deep soil moisture to land use and afforestation in the semi-arid Loess Plateau, China. J. Hydrol. 475, 111-122.

Yang, L., Wei, W., Chen, L., Jia, F., Mo, B., 2012b. Spatial variations of shallow and deep soil moisture in the semi-arid Loess Plateau, China. Hydrol. Earth Syst. Sci. 16, 3199-3217.

Yang, L., Wei, W., Chen, L., Chen, W., Wang, J., 2014. Response of temporal variation of soil moisture to vegetation restoration in semi-arid Loess Plateau, China. Catena 115, 123-133.

Zhu, Y., Shao, M., 2008. Variability and pattern of surface moisture on a small-scale hillslope in Liudaogou catchment on the northern Loess Plateau of China. Geoderma 147, 185-191.

Zhu, H., Shi, Z., Fang, N., Wu, G., Guo, Z., Zhang, Y., 2014. Soil moisture response to environmental factors following precipitation events in a small catchment. Catena 120, 73-80. 